\title{
INFLUENCE OF SURFACE CURRENTS ON POST-NESTING MIGRATION OF GREEN SEA TURTLES NESTING ON WAN-AN ISLAND, PENGHU ARCHIPELAGO, TAIWAN
}

I-Jiunn Cheng

Institute of Marine Biology, National Taiwan Ocean University, Keelung, 202-24, Taiwan, R.O.C.

Yu-Huai Wang

Institute of Applied Marine Physics and Undersea Technology, National Sun Yat-Sen University, Kaoshiung, Taiwan, R.O.C., yhwang@nsysu.edu.tw

Follow this and additional works at: https://jmstt.ntou.edu.tw/journal

Part of the Marine Biology Commons

\section{Recommended Citation}

Cheng, l-Jiunn and Wang, Yu-Huai (2009) "INFLUENCE OF SURFACE CURRENTS ON POST-NESTING MIGRATION OF GREEN SEA TURTLES NESTING ON WAN-AN ISLAND, PENGHU ARCHIPELAGO, TAIWAN," Journal of Marine Science and Technology. Vol. 17: Iss. 4, Article 8.

DOI: 10.51400/2709-6998.1987

Available at: https://jmstt.ntou.edu.tw/journal/vol17/iss4/8

This Research Article is brought to you for free and open access by Journal of Marine Science and Technology. It has been accepted for inclusion in Journal of Marine Science and Technology by an authorized editor of Journal of Marine Science and Technology. 
INFLUENCE OF SURFACE CURRENTS ON POST-NESTING MIGRATION OF GREEN SEA TURTLES NESTING ON WAN-AN ISLAND, PENGHU ARCHIPELAGO, TAIWAN

\section{Acknowledgements}

Ms. Y. R. Cai helped process the data, which is much appreciated. The field data collections were supported by the National Science Council of Taiwan, the Council of Agriculture, the Quanta Education Foundation. YHW appreciated support from the Aim for the Top University Plan. 


\title{
INFLUENCE OF SURFACE CURRENTS ON POST-NESTING MIGRATION OF GREEN SEA TURTLES NESTING ON WAN-AN ISLAND, PENGHU ARCHIPELAGO, TAIWAN
}

\author{
I-Jiunn Cheng* and Yu-Huai Wang**
}

Key words: turtle migration, satellite telemetry, swimming speed, Taiwan Strait.

\begin{abstract}
The relationships between ambient flows and the migration corridors of green turtles (Chelonia mydas) nesting at Wan-an Island, Penghu Archipelago in Taiwan Strait were determined. Six turtles deployed with Argos-linked satellite tags from 1996 to 2004 were used. The ambient flows were derived from the combination of ship board measurements, a global tidal model, and the geostrophic flows derived from sea surface height anomalies. The results showed that there were, basically, three migrating patterns. Turtles that migrated northeastward rode the main surface currents, traveling $2000 \mathrm{~km}$ in a month. The swimming speeds along the track were less than $0.5 \mathrm{~m} \mathrm{~s}^{-1}$. More than half of their migration energy was spent in adjust their headings against the tidal currents. Turtles that travel southward against the current had swimming speeds over $1 \mathrm{~m}$ $\mathrm{s}^{-1}$. These turtles corrected their headings and increased swimming speeds when they encountered oceanic eddies that deflected them from their destination. For the third migration pattern, turtles used the coast landmarks as migration guides, swimming constantly at $0.7 \mathrm{~m} \mathrm{~s}^{-1}$. Their migration distance was proportional to the swimming speed with little influence from the flows in shallow coastal waters. All three patterns showed very good compass sense in migration orientation and the swimming speeds were related to the ambient current.
\end{abstract}

\section{INTRODUCTION}

Adult sea turtles are known to cover long distances between their nesting and foraging grounds $[8,18,32]$. Since the early

\footnotetext{
Paper submitted 04/01/08; revised 07/21/08; accepted 10/21/08. Author for correspondence: Yu-Huai Wang (e-mail: yhwang@nsysu.edu.tw).

*Institute of Marine Biology, National Taiwan Ocean University, Keelung, 202-24, Taiwan, R.O.C.

**Institute of Applied Marine Physics and Undersea Technology, National Sun Yat-Sen University, Kaoshiung, Taiwan, R.O.C.
}

1980s, satellite telemetry has provided detailed information on the life history traits of sea turtles, especially the ocean phases $[9,10,15]$. These data indicate that satellite telemetry is a powerful tool to study the ecology and promote the conservation of sea turtles $[25,38]$.

Experimental studies suggest that a regional map of the geomagnetic field intensity and inclination plays a major role in the open-ocean navigation of sea turtles [27, 28]. Inheritance of a magnetic biocoordinate map, coupled with learning of coastal landscape features, enables the turtles to stay within the major current systems [30]. Windborne and current-transported chemical signatures from the destination site may also play an important role in the mechanism of migration [19, 32], or both [29, 30, 31]. Alerstan et al. [1] suggested that the physical features in the ocean can have positive or negative influence on the long-distance migration of sea turtles. Sea turtles also may use currents as a guide to reach their destinations. Gaspar et al. [13] demonstrated that by use of satellite-derived current estimates and leatherback turtle (Dermochelys coriacea) tracking data, neglecting ocean currents can substantially lead to the wrong track. Consequently, this may affect the identification of foraging areas and the energy budget of the animals. In reviewing 10 years of satellite telemetry data, Luschi et al. [33] found that the post-nesting migratory behaviors of leatherback and loggerhead turtles (Caretta caretta) were very different. The loggerheads undertook a true migration, actively swimming from the nesting ground to specific foraging grounds along the coast, while the leatherbacks made prolonged sojourns across a vast feeding area in the open ocean. The difference is probably due to the different food requirements of the two species.

Because sea turtles are large nektonic organisms capable of controlling their swimming speed and direction, the relationship between turtle migration and surface currents is not straightforward. Previous studies have indicated that several patterns occur. Turtles may swim actively with the currents or, in the case of strong currents, drift with it [3, 27, 32]. Alternately, turtles may swim against weak currents [37], using them as guides to the foraging grounds [33]. Turtles may be disoriented by currents when encountering strong eddies [37], even with the ability to adjust it [14]. 


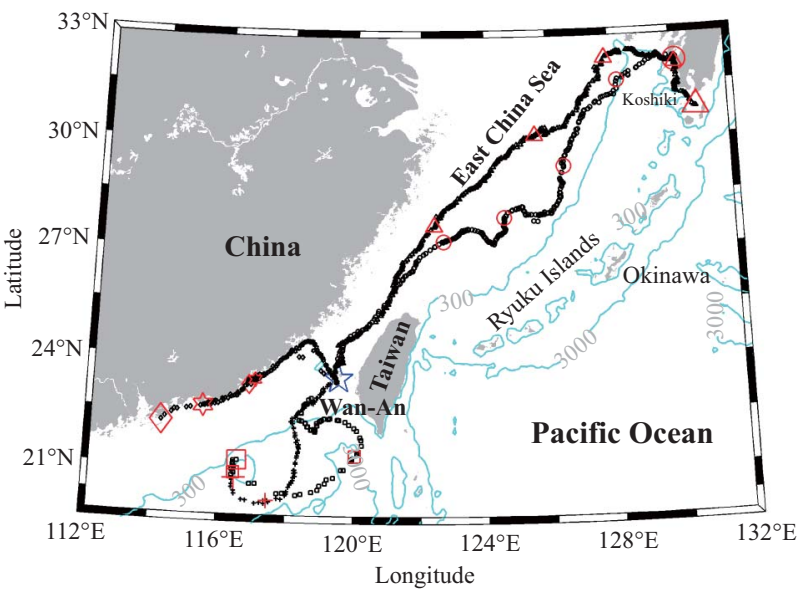

Fig. 1. Area of study and post-nesting migration tracks of six green sea turtles that nested on Wan-an Island (denoted by the star), Taiwan, in 1996-2004. The small symbols on each track are recorded Argos satellite locations for each turtle, while bigger symbols indicate locations at weekly intervals (interpolated). The largest symbols show the termination point of the tracking. Each turtle is designated by a different symbol (circle, square, triangle, diamond, cross, and 6-pointed star).

Wan-an Island of the Penghu Archipelago is located in the southwestern Taiwan Strait (Fig. 1) and is the largest nesting site for green turtles (Chelonia mydas) in Taiwan [6]. Turtles have to face the strong flows in Taiwan Strait when approaching or leaving Wan-an Island. Tidal currents in Taiwan Strait can exceed $1 \mathrm{~m} \mathrm{~s}^{-1}$ with a mean northward velocity of about $0.5 \mathrm{~m} \mathrm{~s}^{-1}[40,41]$. The instantaneous flow reaches its maximum speed in the summer, when it can exceed $1.5 \mathrm{~m} \mathrm{~s}^{-1}$.

The nesting season of green turtles on Wan-an Island is in summer, from mid- to late May until October, peaking in July and August [6] at the time of the strongest surface currents in Taiwan Strait. Post-nesting migration is initiated mainly in August with a variety of headings [7]. Papi [35] suggested that sea turtles generally adopt a combination of vectorial navigation and path integration to reach their destinations. We hypothesize that the turtles leaving Wan-an have a preset migration route and destination after nesting. Taiwan Strait provides a variety of features that could affect how the turtles adjust their migration headings. These include the strong currents in the strait, the land boundaries to the east and west, the open South China Sea with weak currents to the south, and the East China Sea with moderate currents to the north. The purpose of this study is to determine how the strong currents influence the post-nesting migration behavior of green turtles leaving Wan-an Island.

\section{MATERIALS AND METHODS}

\section{Migration Tracks of Satellite Tagged Sea Turtles}

Based on Argos positioning system, results from six green sea turtles post-nesting migration tracks in the Taiwan Strait
Table 1. Sizes of the six satellite tagged green sea turtles (Chelonia mydas) and their post-migration departure dates, migration distances and durations in the Taiwan Strait from 1996 to 2004.

\begin{tabular}{|c|c|c|c|c|c|c|c|c|}
\hline Turtle label & $\begin{array}{c}\text { SCL } \\
(\mathrm{cm})\end{array}$ & $\begin{array}{c}\text { CCL } \\
(\mathrm{cm})\end{array}$ & DD & IMD & $\begin{array}{c}\text { TDA } \\
(\text { days })\end{array}$ & $\begin{array}{c}\text { MDK } \\
(\mathrm{km})\end{array}$ & $\begin{array}{c}\text { RDTS } \\
(\text { days })\end{array}$ & $\begin{array}{c}\text { PVD } \\
(\mathrm{km})\end{array}$ \\
\hline 199806635 & 95 & 102 & $8 / 20$ & $\mathrm{~N}$ & 33 & 1975 & 4 & 1427 \\
\hline 200321891 & 94 & 98 & $8 / 27$ & $\mathrm{~N}$ & 34 & 2267 & 4 & 1390 \\
\hline 199804240 & 99.5 & 103 & $8 / 27$ & $\mathrm{~S}$ & 10 & 735 & 4 & 481 \\
\hline 200421899 & 93.5 & 97 & $8 / 22$ & $\mathrm{~S}$ & 16 & 972 & 6 & 372 \\
\hline 199608352 & 94 & 100 & $8 / 25$ & $\mathrm{NW}$ & 14 & 585 & 3 & 753 \\
\hline 200307128 & 102 & 109 & $8 / 26$ & $\mathrm{NW}$ & 13 & 690 & 5 & 635 \\
\hline
\end{tabular}

Label: year and tag label number. CCL: curved carapace length. SCL: straight carapace length. DD: departure date. IMD: initial migration compass direction $(\mathrm{N}=$ north, $\mathrm{S}=$ south, $\mathrm{W}=$ west $)$. TDA: tracking days by ARGOS. MDK: migration distance in km. RDTS: Residence days in Taiwan Strait. PVD: drifting distance by progressive vector diagram.

from 1996 to 2004 were analyzed (Fig. 1). Sizes of the nesting turtles and their post-migration departure dates, migration distances and durations are given as Table 1. Three types of PTTs (platform terminal transmitter), the ST-6, ST-3, and ST-14 (Telonics; Mesa, Arizona, USA) were used. The PTTs were attached to the carapaces of six turtles by using methods described in Cheng [8]. The data (position in longitude, $x$, and latitude, $y$, times) were screened through a series of criteria to remove the outliers, defined as outside 3 standard deviations of 5-point moving average values. Occasionally, the data showed repeated time records which were also removed. The migration velocities (i.e. $\mathrm{u}$ and $\mathrm{v}$ ) of each turtle were then computed from the distance (i.e. $\delta \mathrm{x}$ and $\delta \mathrm{y}$ ) between two valid consecutive positions divided by the elapsed time (i.e. $\delta \mathrm{t}$ ). Migration speeds greater than the assumed maximum longdistance travel rate for green sea turtles were rejected. Pelletier et al. [36] indicated a maximum migration speed of $3 \mathrm{~km} / \mathrm{hr}$ $\left(0.8 \mathrm{~m} \mathrm{~s}^{-1}\right)$ for sea turtles in the open ocean. We relaxed the criterion of rejection to a maximum speed of $3 \mathrm{~m} \mathrm{~s}^{-1}(10.8$ $\mathrm{km} / \mathrm{hr}$ ). The reason is because the current velocity in Taiwan Strait can reach $2 \mathrm{~m} \mathrm{~s}^{-1}$ that we don't want to exclude any feasible data points. The initial position (star in Fig. 1) is the first position in the Argos tracking record.

Seven location classes (LC) with different accuracies are used by Argos. LC3 is the most accurate location class with errors $<150 \mathrm{~m}$. The other classes are relatively less accurate, with LC2 having an estimated accuracy range from $150 \mathrm{~m}$ to $350 \mathrm{~m}$, LC1 from $350 \mathrm{~m}$ to $1000 \mathrm{~m}$, and LC0 > $1000 \mathrm{~m}$. The location accuracies of LC A and LC B were not estimated, and LC $\mathrm{Z}$ has an unknown accuracy. We verified the LCs and migration tracks as well as migration velocities of each turtle. 
The filtered migration tracks of these 6 turtles are reported here. There were 4 more turtle tracks recorded during the study period, but their migration times and distances were too short that only a few positions were available inside the Straits, and therefore they were not included in the analyses.

The Argos data were Lagrangian, a series of positions marking the combined current and swimming activity of the PTTtagged turtle. The positions were provided via Argos satellites passing overhead at discrete but variable time intervals. In our analyses, the real Argos tracks were compared with computed drift tracks based on flow predictions.

\section{Flow Predictions}

The surface current in Taiwan Strait is composed mainly of tidal currents superimposed on a mean northward ocean current. The mean current is mostly due to intrusion of the $\mathrm{Ku}$ roshio, plus wind driven currents from monsoons [40, 41]. The flows varied with time and space along the migration tracks. We applied a Lagrangian drifter technique [34] to estimate the turtle drifting tracks (apart from swimming) for comparison with the Argos derived migration tracks. The drift track is the PVD (progressive vector diagram) of the computed flow along the migration tracks. This approach is often referred to pseudo-Lagrangian. The PVD is constructed by drawing the first displacement vector in a Cartesian co-ordinate grid based on the local predicted instantaneous current. The second vector is then added to the first vector, its tail sitting at the head of the first vector, and so on.

The computed flows include both the tidal current and the ocean current at the same time and location as the migrating turtles. We have been concerned that the flows in the coastal area may not be accurately represented by satellite data (such as Aviso). Therefore, tidal currents were predicted using a global tidal model [12] and validated with the predicted tidal currents from the analysis of historical ship board ADCP measurements [41]. The tidal currents in the Taiwan Strait calculated by these two methods were within $5 \%$ of error. The global tidal model is a medium-resolution, $0.25 \times 0.25$ degree, developed at Oregon State University. We computed tidal velocities at 1098 locations, each corresponding to an Argos positioning of the turtle tracks. The tidal currents in the Taiwan Strait had a maximum speed of $1.14 \mathrm{~m} \mathrm{~s}^{-1}$, averaged speed of $0.29 \mathrm{~m} \mathrm{~s}^{-1}$ and oscillated along the major NNE-SSW axis of the Strait. The tidal currents in the East China Sea were mostly in NW-SE direction, with a maximum speed of 0.65 $\mathrm{ms}^{-1}$ and averaged speed of $0.19 \mathrm{~m} \mathrm{~s}^{-1}$. The South China Sea had a weak tidal current, with a maximum speed of $0.09 \mathrm{~m} \mathrm{~s}^{-1}$ and averaged speed of $0.03 \mathrm{~m} \mathrm{~s}^{-1}$.

In addition to tidal currents, ocean currents were derived along the turtle tracks. Hwang and Chen [23] derived ocean currents using the T/P SSHA (sea surface height anomaly) for South China Sea. However, satellite data may be biased in shallow coastal waters. Therefore, we used T/P SSHA to derive currents for the open ocean (not covered by sbADCP data). For the shallow Taiwan Strait and vicinity of Taiwan,

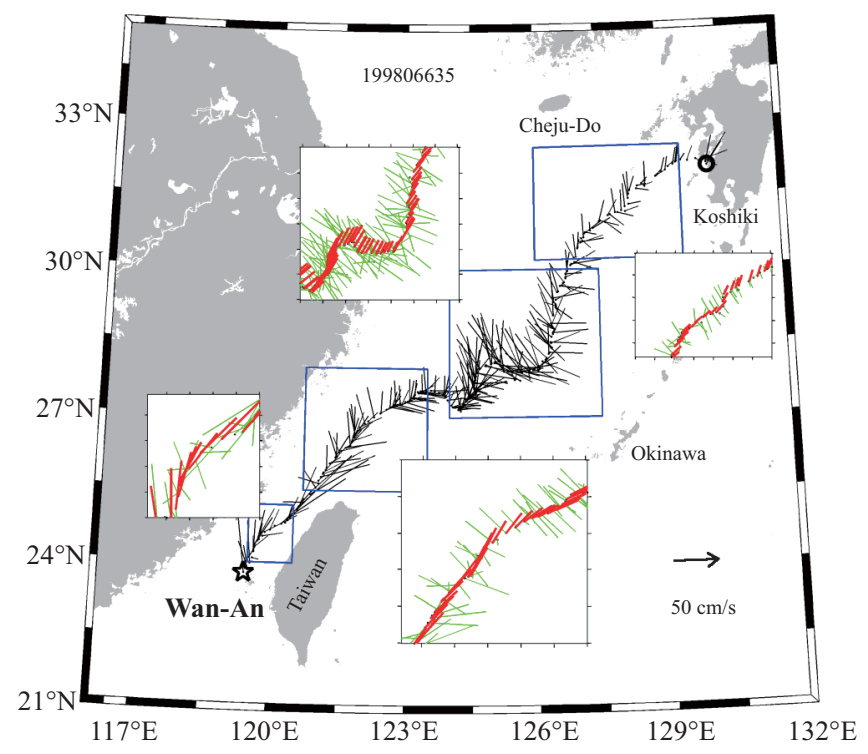

Fig. 2. Stick diagram of ambient currents along green sea turtle (199806635) track in the Taiwan Strait. The inserts show ocean current (thick lines) and tidal current (thin lines) at four sections of the track marked by the boxes.

the ocean currents were derived by a spatial least-squares technique $[40,41]$ based on historical shipboard ADCP data. The area covers $118^{\circ} \mathrm{E}-124^{\circ} \mathrm{E}$ and $21^{\circ} \mathrm{N}-27^{\circ} \mathrm{N}$. A total of over 18000 points of 30-minute averaged data from 1996 to 2003 were used to extract the ocean currents along the migration tracks. The resultant currents were mostly to the north, with a maximum speed of $0.59 \mathrm{~m} \mathrm{~s}^{-1}$ and averaged speed of $0.19 \mathrm{~m} \mathrm{~s}^{-1}$. An objective optimal interpolation technique [4] was applied to combine the data derived from the sbADCP with those from the T/P SSHA as a composite ocean current along the migration tracks. The total flow is the sum of tidal current and ocean current. Figure 2 shows a typical example of derived flows along the track of a northeasterly traveling turtle (label number 199806635). The inserts show that the tidal currents oscillate in the NE-SW direction in the Taiwan Strait, but in the NW-SE direction in the East China Sea region.

The predicted flow velocity (total flow) and migration velocity (based of Argos positions and time gaps) were computed at each position of the six turtles. The drifting track is defined as the PVD of the predicted total flow for each turtle. The swimming velocity at each position is defined as the migration velocity subtracts the predicted flow.

\section{RESULTS AND DISCUSSION}

Our data showed that the six tagged turtles migrated to three different destinations (Fig. 1). The northward migrating turtles (199806635 and 200321891) swam to the northern Taiwan Strait and then to the East China Sea towards Japan. They spent over a month to migrate total distances of $1975 \mathrm{~km}$ and $2267 \mathrm{~km}$, respectively. The overall migration speeds (mean of 
local speeds, not the total distance divided by time) were 0.75 $\mathrm{m} \mathrm{s}^{-1}$ and $0.88 \mathrm{~m} \mathrm{~s}^{-1}$ respectively. These turtles basically swam with the ocean current (Fig. 3). The swimming speeds over the entire corridors were $0.62 \mathrm{~m} \mathrm{~s}^{-1}$ and $0.8 \mathrm{~m} \mathrm{~s}^{-1}$ for these two turtles respectively. If we only considered the ambient flow, the drifting distances (circles in Fig. 3) were $1427 \mathrm{~km}$ and $1390 \mathrm{~km}$ for these two turtles, which accounted for $72 \%$ and $61 \%$ of the total migration distance for each turtle.

The northeastward tracks indicate that the drift (upper left insert in Fig. 3) was almost parallel to that of the migration. In this area, the ocean currents had the same orientation as the tracks, while tidal currents oscillated across the track. Therefore, the parallel tracks of drifting and migration suggested that the turtles might swim to adjust for the deflection of tidal currents while riding along with the ocean currents. The distances between the drifting and the migration tracks at each time interval (lower right insert in Fig. 3) were computed. This can be used as an indicator of the swimming efforts by the turtle to reach their destination. For example, turtle 200321891 swam hard during the first 10 days, as indicated by the steep initial slope of the separation distance curve. The computed swimming speeds in that initial interval were $0.7 \mathrm{~m} \mathrm{~s}^{-1}$ and 0.9 $\mathrm{m} \mathrm{s}^{-1}$ (speeds for the entire corridors were $0.62 \mathrm{~m} \mathrm{~s}^{-1}$ and 0.8 $\mathrm{m} \mathrm{s}^{-1}$ ). The separation distance also provided information on the swimming effort devoted to control the migration orientation. We used the separation distance divided by the travel time as indication of the along-track effective swimming speeds (efforts to reach destination), which were $0.33 \mathrm{~m} \mathrm{~s}^{-1}$ and $0.49 \mathrm{~m} \mathrm{~s}^{-1}$ in the first 10 days for turtles 199806635 (280 $\mathrm{km})$ and $200321891(420 \mathrm{~km})$, respectively. This means that due to the variations in surface flow caused by the tidal current, the turtles spent nearly half of their effort, likely, to adjust their headings. Similar behaviors of turtles riding along the ocean current were observed in the post-nesting migrations of green turtles nest at Ascension Island [22] and olive ridley turtles (Lepidochelys olivacea) in the North Pacific Ocean [37]. Our analysis suggested that the green sea turtle might spend substantial amount of energy in adjustment of their headings, in additional to energy consumed by vertical moving and diving.

In contrast, two turtles (199804240 and 200421899) migrated initially southward against the ocean currents, traveled in a clockwise circle and then moved to the vicinity of Dongsha Atoll (Fig. 4). The overall swimming speeds were 0.98 and $0.8 \mathrm{~m} \mathrm{~s}^{-1}$ for turtles 199804240 and 200421899 , respectively. The rapid swimming speed suggested that these two turtles spent great effort to swim against the ocean current in order to reach their final destinations. The distances of swimming and drifting were very different as shown in Fig. 4 (upper left insert). In contrast to the northeastward migrating turtles that took advantage of the current drift, the southward migrating turtles spent $65 \%$ and $38 \%$ more energy to travel.

In addition, both turtles migrated on a 'detour' route, likely influenced by the eddies in the South China Sea, before reaching the vicinity of Dongsha Atoll. There is a permanent anticyclonic eddy in that region $[5,26]$. The coral reefs within the
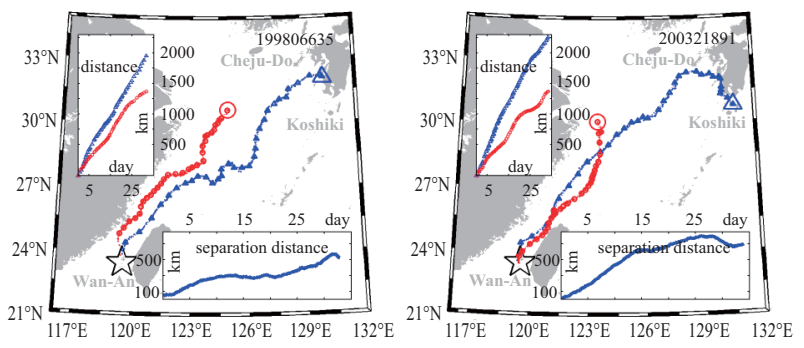

Fig. 3. Tracks of two green sea turtles that migrated northeasterly with the ocean current with slight adjustments by tidal currents in the Taiwan Strait. Turtle identification numbers are in the upper right corner of each plot. Stars mark the initial position. Triangles indicate interpolated daily positions on the actual migrating routes. Circles are the interpolated daily positions on the drifting PVD (progressive vector diagram) based on calculated flows along the migration routes. Inserted are the distances (upper left) of travel and the distances apart (lower right) between the drifting and migration paths.
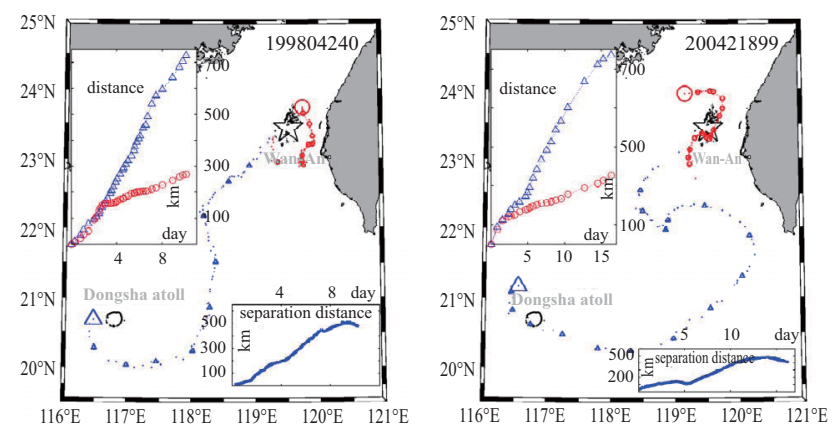

Fig. 4. Two green sea turtles that migrated south, swimming against the ocean currents in the Taiwan Strait. Symbols and insets are the same as in Fig. 3. Both turtles migrated on a 'detour' route, likely caught by eddies in the South China Sea, before reaching the vicinity of Dongsha Atoll.

Dongsha Atoll might be their foraging sites. The detour route had an interesting turning point. The swimming speeds reached $1.12 \mathrm{~m} \mathrm{~s}^{-1}$ and $1.01 \mathrm{~m} \mathrm{~s}^{-1}$ on the 4th and 6th day for turtles 199804240 and 200421899, respectively. The increases of swimming speed also indicated in the large slopes of separation distance (days 4-7 and 6-10 in the lower insert of Fig. 4). These data suggest that the turtles may sense the ocean currents carrying them away from their destination. We found that the southward migrating green turtles persistently contributed a large effort to swim against the current and adjust their headings to reach Dongsha Atoll. Similar results were found for the post-nesting migration of one green turtle departing from Tortuguero, Costa Rica [39]. Despite having only data set for one turtle, Gaspar et al. [13] suggested that a leatherback turtle tended to maintain a stable heading with remarkable compass sense even in the presence of strong currents.

Two turtles (199608352 and 200307128) migrated northwest across the Taiwan Strait, then swam southwest along the 

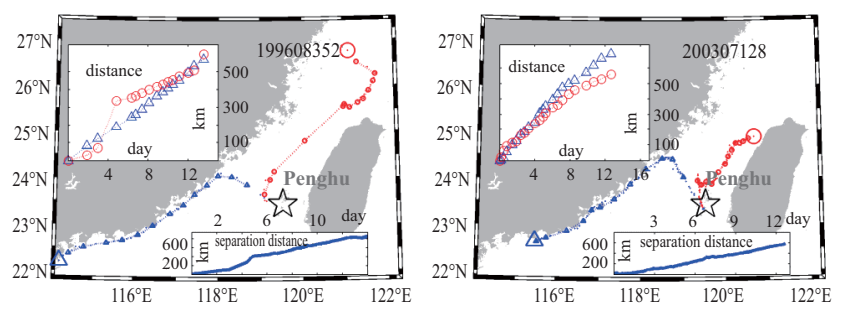

Fig. 5. Two green sea turtles that migrated northwest across the Taiwan Strait and then swam southwest along the coast of southeast China. Symbols and insets as in Fig. 3. The initial migration direction across the straits appeared to be related to the flow direction. After reaching coastal waters, flow had little influence on their migration routes.

coast of China toward Hainan Island (Fig. 5). Their initial headings were deflected to the northwest by the cross-path flow. However, these two turtles managed to reach the southwest coast of China after some displacement to the northeast in Taiwan Strait. The coastline seemed to direct the subsequent migration route. After reaching the coastal water, the flows had little influence on their migration route. The turtles swam through the whole course with steady speeds of $0.62 \mathrm{~m} \mathrm{~s}^{-1}$ and $0.76 \mathrm{~m} \mathrm{~s}^{-1}$, respectively. The current velocities were low near the coast, and therefore the turtles neither rode the current (like those moving north) nor fought against it (like those moving south). The swimming distance simply reflected the required effort.

Results of this study indicate that the migrating green sea turtles were able to adjust their swimming speeds and orientations in response to the ambient flow conditions in order to reach their foraging sites. However, they were unable to remove these influential factors completely as indicted by the model studies of Girard et al. [14]. In spite of this, the final destinations are set regardless of the flow conditions. They might use the geomagnetic map of the earth, coastal landmark features, mesoscale oceanographic features, geomorphology of ocean basins, airborne and/or waterborne chemicals from the destination as the cues for migration $[2,16,29]$. Based on the physical measurements (curved carapace length and straight carapace length) of the six female adult turtles, we found no obvious size effect on the swimming or initial orientation of migrations.

Animals migrate long distances to exploit different resources temporarily or spatially, or avoid depletion local resource, or reproduction $[1,11]$. They spend a lot of energy during the migration to enhance the fitness of the population. Like most marine megafauna, sea turtles fast or reduce feeding level during their reproductive migration [17]. Thus, it is important to delineate the influence of hydrodynamic regimes to the migration behavior of sea turtles, especially in the region with strong surface current systems like Taiwan Straits. Then, one can understand the adaptive strategies of sea turtles in different marine environments.

One of the difficulties in comparing ambient flow with the swimming ability of sea turtles is the time scale of motion. The tidal variations are mainly due to semidiurnal (12 hr) and diurnal ( $24 \mathrm{hr}$ ) periods, so that the flow changes in direction and magnitude within a few hours. This is especially significant in Taiwan Strait, because the tidal flow (on the order of $\left.1 \mathrm{~m} \mathrm{~s}^{-1}\right)$ is much stronger than the mean flow $\left(0.5 \mathrm{~m} \mathrm{~s}^{-1}\right)$. However, the time elapsed between satellite data records along the migration tracks may range from a few minutes to several days. In order to study the influence of flow on the swimming behavior of turtles, we combined flow data from tidal predictions, geostrophic flow derived from satellite-measured SSHA and shipboard ADCP measurements. The errors from these combined calculations are difficult to estimate. High frequency data on the migration track are needed for more detailed study of the influence of flow. The actual trajectories may take zig-zag patterns caused by tidal oscillation. In addition, the turtles may spend long hours diving, when no tracking data were received by Argos [20, 24]. The swimming speed computations based on migration tracks should be 3-dimensional (i.e. x y and depth), which would be more representative of actual turtle behavior. We need detailed information for the diving behavior (e.g. depth, time and pattern).

\section{ACKNOWLEDGMENTS}

Ms. Y. R. Cai helped process the data, which is much appreciated. The field data collections were supported by the National Science Council of Taiwan, the Council of Agriculture, the Quanta Education Foundation. YHW appreciated support from the Aim for the Top University Plan.

\section{REFERENCES}

1. Alerstan, T., Hedenström, A., and Akesson, S., "Long-distance migration: evolution and determinants," Oikos, Vol. 103, pp. 247-260 (2003).

2. Avens, L. and Lohmann, K. J., "Navigation and seasonal migratory orientation in juvenile sea turtles," Journal of Experimental Biology, Vol. 207, pp. 1771-1778 (2004).

3. Bolten, A. B., Bjorndal, K. A., Martins, H. R., Dellinger, T., Biscotto, M. J., Encalada, S. E., and Bowen, B. W., "Trans Atlantic developmental migrations of loggerhead sea turtles demonstrated by mtDNA sequence analysis," Journal of Applied Ecology, Vol. 8, pp. 1-7 (1998).

4. Bretherton, F. P., Davis, R. E., and Faundry, C. B., "A technique for objective analysis and design of oceanographic experiments applied to MODE-73," Deep-Sea Research, Vol. 23, pp. 559-582 (1976).

5. Caruso, M. J., Gawarkiewicz, G. G., and Beardsley, R. C., "Interannual variability of the kuroshio intrusion in the South China Sea," Journal of Oceanography, Vol. 62, pp. 559-575 (2006).

6. Chen, T. H. and Cheng, I. J., "Breeding biology of the green turtle, Chelonia mydas (Reptilia: Cheloniidae) at Wan-an Island, Peng-Hu Archipelago, Taiwan. I. Nesting ecology," Marine Biology, Vol. 124, pp. 9-15 (1995).

7. Cheng, I. J., "Current sea turtle research and conservation in Taiwan," Proceedings of the Western Pacific Sea Turtle Cooperative Research and Management Workshop. Honolulu, U.S.A. pp. 185-190 (2002).

8. Cheng, I. J., "Post-nesting migrations of green turtle (Chelonia mydas) at Wan-an Island, Penghu Archipelago, Taiwan," Marine Biology, Vol. 137, pp. 747-754 (2000). 
9. Cooke, S. J., "Biotelemetry and biologging in endangered species research and animal conservation: relevance to regional, national and IUCN Red List threat assessments," Endang Species Research, Vol. 4, pp. 165-185 (2008).

10. Craig, P., Parker, D., Brainard, R., Rice, M., and Balazs, G. H., "Migrations of green turtles in the Central South Pacific," Biological Conservation, Vol. 116, pp. 433-438 (2004).

11. Eckert, S. A., "High use oceanic areas for Atlantic leatherback sea turtles (Dermochelys coriacea) as identified using satellite telemetered location and dive information," Marine Biology, Vol. 149, pp. 1259-1267 (2006).

12. Egbert, G. D. and Erofeeva, S. Y., "Efficient inverse modeling of barotropic ocean tides," Journal of Atmospheric and Oceanic Technology, Vol. 19, pp. 183-204 (2002).

13. Gaspar, P., Georges, J. Y., Fossette, S., Lenoble, A., Ferraroli, S., and Maho, Y. L., 2006. "Marine animal behaviour: neglecting ocean currents can lead us up the wrong track," Proceedings of the Royal Society B, Vol. 3623, pp. 1-5 (2006).

14. Girard, C., Sudre, J., Benhamou, S., Ross, D., and Luschi, P., "Homing in green turtle Chelonia mydas: oceanic currents acts as a constraint rather than as an informat in source," Marine Ecology Progress Series, Vol. 322 , pp. 281-289 (2006)

15. Godley, B. J., Blumenthal, J. M., Broderick, A. C., Cyone, M. S., Godfrey, M. H., Hawies, L. A., and Witt, M. J., "Satellite tracking of sea turtles: where have we been and where do we go next?" Endang Species Research, Vol. 4, pp. 3-22 (2008).

16. Hays, G. C., Akesson, S., Broderick, A. C., and Glen, F., "Island-finding ability of marine turtles," Proceedings of the Royal Society B, Vol. 270, pp. S5-S7 (2003).

17. Hays, G. C., Broderick, A. C., Glen, F., and Godley, B. J., "Change in body mass associated with long-term fasting in a marine reptile: the case of green turtle (Chelonia mdas) at Ascension Island," Canadian Journal of Zoology, Vol. 80, pp. 1299-1302 (2002).

18. Hays, G. C., Broderick, A. C., Godley, B. J., Lovell, P., Martin, C., McConnell, B. J., and Richardson, S., "Biphasal long-distance migration in green turtle," Animal Behaviour, Vol. 64, pp. 895-898 (2002).

19. Hays, G. C., Dray, M., Quaife, T., Smyth, T. J., Mironnet, N. C., Lusch, P., and Barnsley, M. J., "Movements of migrating green turtles in relation to AVHRR derived sea surface temperature," International Journal of Remote Sensing, Vol. 22, pp. 1403-1411 (2001).

20. Hays, G. C., Hobson, V. J., Metcalfe, J. D., Righton, D., and Sirns, D. W., "Flexible foraging movements of leatherback turtles across the North Atlantic Ocean.” Ecology, Vol. 67, pp. 2647-2656 (2006).

21. Hays, G. C., Houghton, J. D. R., Issacst, C., Lloyd, K. C., and Lovell, P. "First records of oceanic dive profile for leatherback turtles, Dermochelys coriacea, indicate behavioural plasticity associated with long-distance migration," Animal Behaviour, Vol. 67, pp. 723-743 (2004).

22. Hays, G. C., Luschi, P., Papi F., del Seppia, C., and Marsh, R., "Changes in behaviour during the inter-nesting period and post-nesting migrations for Ascension Island green turtles," Marine Ecology Progress Series, Vol. 189, pp. 263-273 (1999).

23. Hwang, C. W. and Chen, S. A., "Circulations and eddies over South China Sea derived from TOPEX/Poseidon altimetry," Journal of Geophysical Research, Vol. 105, pp. 23943-23965 (2000).

24. James, C. J., Davenport, J., and Hays, G. C., "Expanded thermal niche for a diving vertebrate: a leatherback turtle diving into near-freeze water," Journal of Experimental Marine Biology and Ecology, Vol. 335, pp. 221-226 (2006).

25. James, M. C., Ottensmeyer, C. A., and Myers, R. A., "Identification of high-use habitat and threats to leatherback sea turtles in northern waters: new direction for conservation," Ecology Letters, Vol. 8, pp. 195-201 (2005).

26. Liang, W. D., Tang, T. Y., Yang Y. J., Ko M. T., and Chuang, W. S. "Upper-ocean currents around Taiwan," Deep-Sea Research II, Vol. 50, pp. 1085-1105 (2003).

27. Lohmann, K. J. and Lohmann, C. M. F., "Sea turtles, lobsters, and magnetic maps," Marine and Freshwater Behaviour and Physiology, Vol. 39, pp. 49-64 (2006).

28. Lohmann, K. J., Lohmann, C. M. F., Ehrhart, L. M., Bagley, D. A., and Swing, T., "Geomagnetic map used in sea turtle navigation," Nature, Vol. 428, pp. 909 (2004).

29. Lohmann, K. J., Lohmann, C. M. F., and Putman, N. F., "Magnetic maps in animals, nature's GPS," Journal of Experimental Biology, Vol. 210, pp. 3697-3705 (2007).

30. Lohmann, K. J., Luschi, P., and Hays, G. C., "Global navigation and island-finding in sea turtles," Journal of Experimental Marine Biology and Ecology, Vol. 356, pp. 83-95 (2008).

31. Luschi, P., Benhamon, S., Girard, C., Ciccione, S., Roos, D., Sudre, J., and Benvenutt, S., "Marine turtle using geomagmetic cues during openocean homing," Current Biology, Vol. 17, pp. 126-133 (2007).

32. Luschi, P., Hays, G. C., and Papi, F., "A review of long-distance movements by marineturtles, and the possible role of ocean currents," Oikos Vol. 103, pp. 293-302 (2003).

33. Luschi, P., Lutjehavms, J. R. E., Lambardi, P., Mencacci, R., Hughes, G. R., and Hays, G. C., "A review of migratory behaviour of sea turtles off Southeastern Africa," South African Journal of Science, Vol. 102, pp. 51-58 (2006).

34. Molcard, A., Piterbarg, G., and Ozgokmen, M., "Assimilation of Lagrangian data in Eulerian models," Journal of Geophysical Research, 108 , 3056, doi:10.1029/2001JC001240 (2003).

35. Papi, F., "Navigation of marine, freshwater and coastal animals: concepts and current problems," Marine and Freshwater Behaviour and Physiology, Vol. 39, pp. 3-12 (2006).

36. Pelletier, D., Roos, D., and Ciccione, S., "Note: Oceanic survival and movements of wild and captive-reared immature green turtles (Chelonia mydas) in the Indian Ocean," Aquatic Living Resources, 16, pp. 35-41 (2003).

37. Polovina, J. J., Balazs, G. H., Howell, E. A., Parker, D. M., Seki, M. P., and Dutton, P. H., "Forage and migration habitat of loggerhead (Caretta caretta) and olive ridley (Lepidochelys olivacea) sea turtles in the central North Pacific Ocean," Fisheries Oceanography, Vol. 13, pp. 31-51 (2004).

38. Polovina, J. J., Kobayashi, D. R., Parker, D. M., and Balazs, G. H., "Turtles on the edge: movement of loggerhead turtles (Caretta caretta) along oceanic fronts, spanning longline fishing grounds in the central North Pacific, 1997-1998," Fisheries Oceanography, Vol. 9, pp. 71-82 (2000).

39. Troëng, S., Evans, D. R., Harrison, E., and Lagueux, C. J., "Migration of green turtle Chelonia mydas from Tortuguero, Costa Rica," Marine Biology, Vol. 148, pp. 435-447 (2005).

40. Wang, Y. H., Chiao, L. Y., Kamazima, M., and Wang, D. P., "Analysis of flow at the gate of Taiwan Strait," Journal of Geophysical Research, Vol. 109, C02025, doi:10.1029/2003JC001937 (2004).

41. Wang, Y. H., Jan, S., and Wang, D. P., "Transports and tidal current estimates in the Taiwan Strait from shipboard ADCP observations (1999-2001)," Estuarine, Coastal and Shelf Science, Vol. 57, pp. 193-199 (2003). 